\title{
Longevity, Lifetime Pig Production and Productivity, and Age at First Conception in a Cohort of Gilts Observed over Six Years on Commercial Farms
}

\author{
Yuzo KOKETSU, Hiroshi TAKAHASHI ${ }^{1)}$ and Katsuyoshi AKACHI ${ }^{1)}$ \\ Department of Clinical and Population Sciences, University of Minnesota, St. Paul 55108, U.S.A. and ${ }^{1)}$ Global Pig Farms, 800 \\ Kamihakodate, Hokkitsu-mura, Gunma 377, Japan
}

(Received 24 September 1998/Accepted 19 May 1999)

ABSTRACT. An observational cohort study was conducted using a producer group of 33 farms selected based on their completeness of reproduction data, including dates of birth, entry to a herd, and removal. Average lifetime pig production and parity at removal in a cohort of 2,265 females born in 1990 were 67.2 pigs born alive and 5.6 parities, respectively. Approximately $90 \%$ of farrowings occurred from the second through the fourth year from birth. Farrowing rates between parities of 2 and 4 were higher than other parities, and pigs born alive from parities 3 to 5 were the greatest among parities. The 10th and 90th percentiles of age at first conception were 227 and 322 days. Increasing the age at first mating was associated with low farrowing rate $(\mathrm{P}<0.01)$ in parity 0 . Older age at first conception was associated with lower parity at removal, shorter reproductive herd life, and fewer lifetime pigs born alive $(\mathrm{P}<0.01)$. Of the 2,265 breeding females, $253(11.2 \%)$ were re-mated at parity 0 and farrowed. These sows with a record re-mating at parity 0 had lower parity at removal, less lifetime pig production and lower lifetime productivity than those with no re-mating at parity $0(\mathrm{P}<0.01)$. It is recommended that unbred gilts 230 days of age or older should be mated soon.-KEY wORDs: culling, farrowing rate, longevity, productivity, sow.

High average parity at removal or longevity has been associated with high breeding herd productivity [2]. Parity of culled sows or longevity has been observed as a measurement averaged during a certain period using females born in different years. Multiple year data collected from females born during several years tend to accumulate more parity 1 sows than old parity sows. In previous reports $[4$, 12], parity 1 sows were reported to have the highest frequency of culling, although culling at parity 0 (gilt) was not well documented.

Standards or targets of longevity measurements in swine breeding herds are not well reported. Furthermore, longevity, changes of production and culling patterns from gilt entry to removal have not been well documented in the group of females born in the same year. Averages of production measurements provide producers or veterinarians with an overview of their breeding herd performance but not an understanding of production pattern changes over the years.

Age at first conception is a possible factor affecting longevity [7] and lifetime pig production. Previous research on age at first mating has not examined farrowing rate at parity 0 (gilts). The objectives in this observational study were to evaluate: 1) production and culling patterns of sows over six years, 2) the effect of age at first conception on longevity, and lifetime pig production, and 3) the effect of age at first mating on farrowing rate in gilts (parity 0 ).

\section{MATERIALS AND METHODS}

This observational study was designed to be a cohort study over 6 years. A cohort is defined as a group of individuals who have something in common when they are first assembled [10] in epidemiology. Our cohort was a group of females all born in 1990. An integrated producer group was selected based on the completeness of reproduction data including dates of birth, and entry into a herd and removal. The producer group contained 80 breeding herds using lactation and gestation diets of the same formulation based primarily on corn and soybean meal, and replacement gilts from the breeding stock (F1 female of Large While $\mathrm{x}$ Landrace) farm. Calculated compositions in the lactation diet were crude protein: $18.1 \%$, calcium: $1.0 \%$, phosphorus: $0.8 \%$, and metabolizable energy: $3,290 \mathrm{kcal} /$ $\mathrm{kg}$, while compositions in the gestation diets were crude protein: $13.2 \%$, calcium: $0.9 \%$, phosphorus: $0.8 \%$, and metabolizable energy: $3,180 \mathrm{kcal} / \mathrm{kg}$. Natural mating was used on all farms. Producers were strongly recommended to first breed gilts at 8 months or older, or at the third estrus detected after entry into a farm during the study period. No pharmacological treatment inducing oestrus for gilts was used. Sows on all farms were housed during gestation and farrowed indoors. Dates of birth, entry, removal, breeding events, farrowing events, and weaning events were reported to their bureau service via facsimile on a weekly basis. Data was entered into the computerized production record keeping system, PigCHAMP ${ }^{\circledR}$ (St. Paul, University of Minnesota, U.S.A.). Of 80 farms, only 33 farms had complete data from January 1990 to October 1996. No outbreaks of reproductive diseases were observed on these farms during the study period.

Definitions: Age at first service was defined as the age in days at which the female was mated for the first time in her life, and age at first conception was defined as the age in days at which the female was mated for the first time and subsequently farrowed [1]. Parity 0 female (gilt) was 
defined as a breeding female entered into a herd but not farrowed. Parity 1 female (sow) was defined as a female farrowed for the first time but not farrowed for the second litter. Parity 2 and greater females were defined in the same manner as parity 1 . Four birth periods were arbitrarily defined: January to March (565 females), April to June (427 females), July to September ( 726 females), and October to December (547 females). The 33 farms received replacement gilts during all four periods. Female life day was defined as the difference between birth date and removal date. Reproductive herd life day was defined as the interval from age at first service to removal. Lifetime pig production was defined as the sum of the number of pigs born alive for a sow over all her parities. Lifetime and reproductive herd day productivity was assessed as lifetime pig production divided by female life day and reproductive herd days $x$ 100 , respectively. In addition, mated gilts were categorized into two groups that succeeded in farrowing (SUCC) or returned to service (REPEAT) after the first mating.

Statistical analysis: The UNIVARIATE and FREQ procedures [8] were used to obtain descriptive statistics and frequency distributions of parity at removal, parity at farrowing, and farrowing rate by parity. The GLM procedure in SAS was used to determine the effects of birth periods on ages at first service and conception, and to investigate the effects of age at first conception on litter size, longevity, lifetime pig production and lifetime productivity. Using the CATMOD procedure in SAS, logistic regression analysis was used to determine the effect of age at first service on farrowing rate. The dependent variable was dichotomous, and defined as whether or not a breeding female farrowed after mating [6]. The statistical models included age at first service or conception, birth period and farm. Farm was used to adjust for farm-to-farm variation. A quadratic effect of ages was checked if significant $(\mathrm{P}<0.05)$. Fisher's protected least significant difference test [11] was used for comparisons in production measurements by parity and the group of REPEAT and SUCC. Contrasts in the CATMOD of SAS were used for comparisons in the farrowing rate. Standard error of farrowing rate was obtained by the square root of $p(1-p)$ divided by $n$, where $\mathrm{p}$ and $\mathrm{n}$ are the probability of an occurrence and sample numbers, respectively [11].

\section{RESULTS}

Of 2,453 gilts born in 1990 across 33 farms, 188 gilts $(7.6 \%)$ had no mating records (Table 1$)$. The remaining 2,265 females represented 13,509 matings. Of 2,265 females, 168 females $(7.4 \%)$ were mated and removed without farrowing. Of the original 2,453 gilts, only 2,097 females $(85.5 \%)$ were mated and farrowed at parity 1 . These sows produced 140,958 pigs born alive from 1990 to 1996, and all females were culled before July 1996.

Parity distributions of farrowed sows over the 6-year period from birth are presented in Table 2. The highest production of farrowed sows (39\%) were in the second year, and approximately $90 \%$ of total farrowings occurred in the three years from the second to fourth year. Furthermore, approximately $86 \%$ of farrowings were from parities 1 to 6 (Table 2). Farrowing rate and pigs born alive by parity in the cohort of females are presented in Fig. 1. Farrowing rates between parities 2 and 4 were higher than other parities $(\mathrm{P}<0.01)$, while pigs born alive from parities 3 to 5 were the greatest among parities $(\mathrm{P}<0.01)$. Frequency distribution of parity at removal is presented in Fig. 2. Females were culled most at parities 7 and 8 (14.1 and 13.9\%). The recorded reasons for culling were old age $(39.2 \%)$, reproductive failure $(24.5 \%)$, locomotive failure $(8.7 \%)$, not recorded $(7.7 \%)$ and others $(19.9 \%)$.

The ranges of 10th to 90th percentiles of age at first service and conception were 224 to 294 days, and 227 to 327 days, respectively (Table 1). Age at conception was not associated with litter size (pigs born alive) at any parities $(\mathrm{P}>0.1)$, while older age at first service was associated with lower farrowing rate at parity $0(\mathrm{P}<0.01$; logistic coefficient $=0.003 \pm 0.001 \mathrm{SE}$; likelihood ratio $=1.0)$, but not at other parities $(\mathrm{P}>0.1)$. Age at first conception was negatively associated with parity at removal $(P=0.01$; regression coefficient $\left.=-0.004 \pm 0.001 \mathrm{SE} ; \mathrm{R}^{2}=0.15\right)$, female life

Table 1. Descriptive statistics of breeding females born in the same year

\begin{tabular}{lcrrrr}
\hline & & & & \multicolumn{2}{c}{ Percentile } \\
\cline { 4 - 6 } & no. & Mean & s.d. & 10 & 90 \\
\hline Age at entry, days & 2,453 & 184.0 & 29.8 & 152 & 227 \\
Age at first mating, days & 2,265 & 256.2 & 33.2 & 224 & 294 \\
Age at first conception, days & 2,097 & 262.7 & 42.3 & 226 & 310 \\
Parity at removal & 2,265 & 5.6 & 3.1 & 1 & 9 \\
Female life day & 2,265 & 1,138 & 439 & 439 & 1,675 \\
Reproductive herd life day & 2,265 & 882 & 442 & 171 & 1,430 \\
Lifetime pigs born alive & 2,097 & 67.2 & 34.1 & 15 & 110 \\
Lifetime still born pigs & 2,097 & 7.0 & 6.2 & 1 & 15 \\
Lifetime mummified piglets & 2,097 & 0.9 & 1.6 & 0 & 3 \\
Average pigs born alive/parity & 2,097 & 10.8 & 2.17 & 8.3 & 13.3 \\
Lifetime productivity, pigs/100 days & 2,097 & 5.2 & 1.6 & 2.8 & 7.1 \\
Reproductive herd life productivity, & 2,097 & 6.8 & 1.7 & 4.8 & 8.8 \\
pigs/100 days & & & & & \\
\hline
\end{tabular}


Table 2. Parity distribution (\%) of farrowed sows over years of life from birth ${ }^{\text {a }}$

\begin{tabular}{|c|c|c|c|c|c|c|c|c|c|c|c|c|}
\hline \multirow[b]{2}{*}{ Year } & \multicolumn{12}{|c|}{ Parity } \\
\hline & 1 & 2 & 3 & 4 & 5 & 6 & 7 & 8 & 9 & 10 & 11 & Total \\
\hline Birth & 8.1 & 0 & 0 & 0 & 0 & 0 & 0 & 0 & 0 & 0 & 0 & 8.1 \\
\hline $2 \mathrm{nd}$ & 9.5 & 16.2 & 13.3 & 0 & 0 & 0 & 0 & 0 & 0 & 0 & 0 & 39.0 \\
\hline $3 \mathrm{rd}$ & 0 & 0.1 & 1.9 & 13.8 & 11.9 & 3.7 & 0 & 0 & 0 & 0 & 31.4 & \\
\hline 4th & 0 & 0 & 0 & 0.1 & 0.5 & 6.5 & 7.1 & 3.4 & 0 & 0 & 0 & 17.6 \\
\hline 5 th & 0 & 0 & 0 & 0 & 0 & 0 & 0.1 & 0.7 & 2.4 & 0.4 & 0.1 & 3.7 \\
\hline 6th & 0 & 0 & 0 & 0 & 0 & 0 & 0 & 0 & 0 & 0.1 & 0.1 & 0.2 \\
\hline Total & 17.6 & 16.3 & 15.2 & 13.9 & 12.4 & 10.2 & 7.2 & 4.1 & 2.4 & 0.5 & 0.2 & 100.0 \\
\hline
\end{tabular}

a) Less than $0.1 \%$ are not shown.

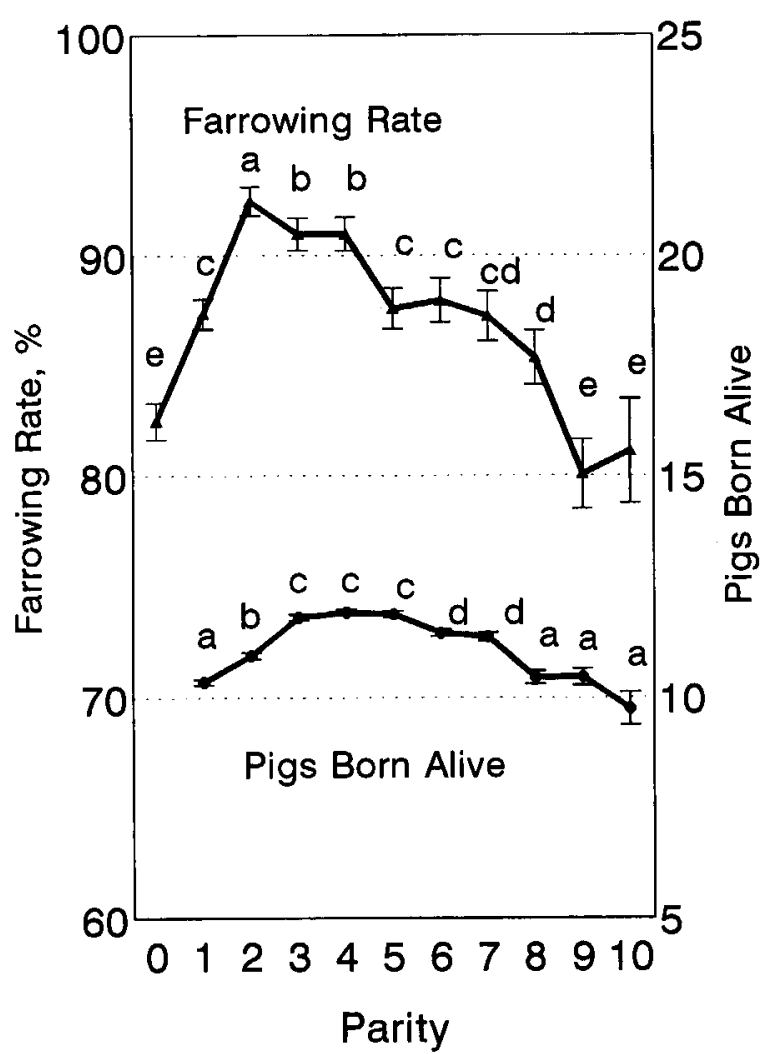

Fig. 1. Pigs born alive and farrowing rate by parity in a cohort of females $(n=2,453)$ born in the same year. abcde Values within a line lacking a common superscript differ $(\mathrm{P}<0.01)$.

day $(\mathrm{P}=0.04$; regression coefficient $=-0.433 \pm 0.220 \mathrm{SE}$; $\left.\mathrm{R}^{2}=0.15\right)$, lifetime pigs born alive $(\mathrm{P}<0.01$; regression coefficient $\left.=-0.051 \pm 0.019 \mathrm{SE} ; \mathrm{R}^{2}=0.16\right)$, lifetime pig productivity $(\mathrm{P}<0.01$; regression coefficient $=-0.007 \pm$ $\left.0.001 \mathrm{SE} ; \mathrm{R}^{2}=0.17\right)$, and reproductive herd life productivity $\left(\mathrm{P}<0.01\right.$; regression coefficient $=-0.005 \pm 0.001 \mathrm{SE} ; \mathrm{R}^{2}=$ $0.16)$. However, reproductive herd life day was not affected by age at first conception $(\mathrm{P}>0.1)$. No quadratic effect of age was found $(\mathrm{P}>0.1)$ in any models.

Of 2,097 females, 253 gilts $(12.1 \%)$ were in the REPEAT group. Gilts in the REPEAT group were older age at first conception $(\mathrm{P}<0.01)$, had lower lifetime farrowing rate

\section{Culled Female, \%}

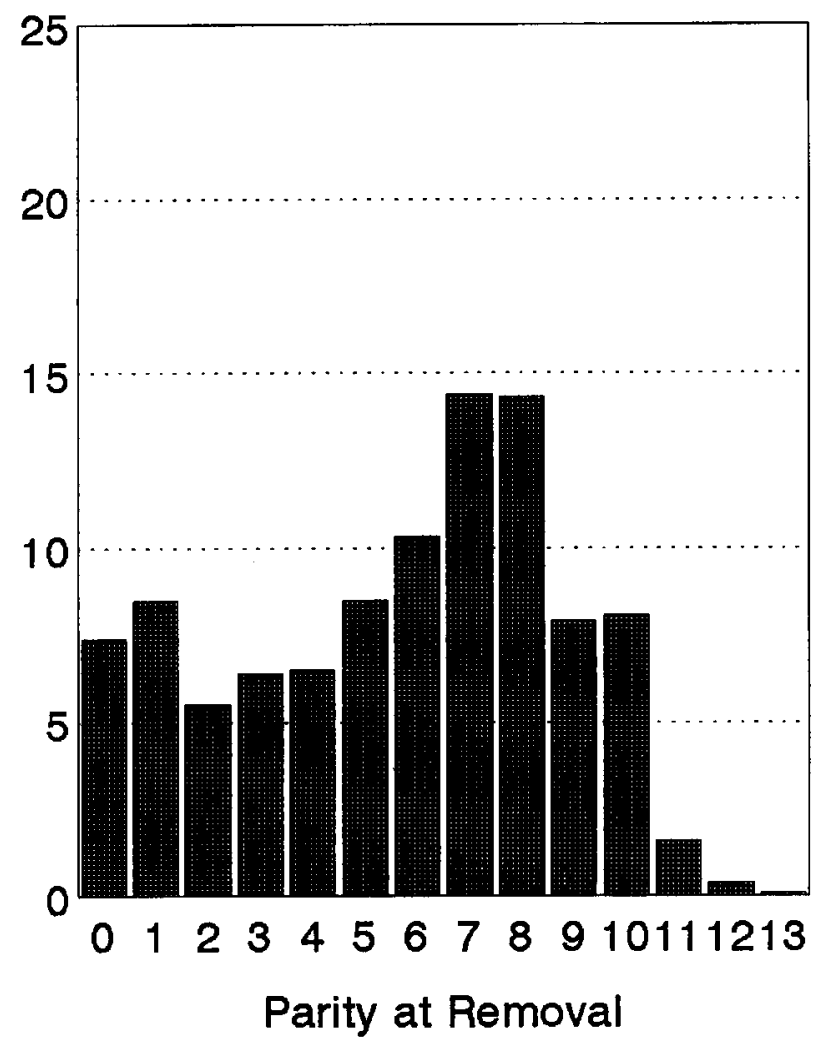

Fig. 2. Frequency distribution of parity when 2,453 females were culled.

$(\mathrm{P}=0.03)$, fewer average pigs born alive $(\mathrm{P}=0.02)$, lower parity at removal $(\mathrm{P}<0.01)$, fewer lifetime pig born alive $(\mathrm{P}<0.01)$, shorter female life day $(\mathrm{P}=0.08)$, shorter reproductive herd life day $(\mathrm{P}=0.08)$, less lifetime productivity $(\mathrm{P}<0.01)$, and less reproductive herd productivity $(\mathrm{P}<0.01)$ than those in the SUCC group (Table 3 ). Excluding these REPEAT gilts, the age at first conception was not found to be associated with parity at removal, reproductive herd day, and lifetime pig born alive production $(\mathrm{P}>0.1)$. However, age at conception was positively associated with female life day $(\mathrm{P}<0.01$; regression coefficient $=0.937 ; \mathrm{R}^{2}=0.16$ ). In addition, birth 
Table 3. Least square means of longevity, lifetime production and productivity by gilts returned to service $(n=253)$ or gilts conceived $(n=1,844)$ after the first mating at parity 0

\begin{tabular}{lcc}
\hline & $\begin{array}{c}\text { Gilts conceived at the first } \\
\text { mating }\end{array}$ & Gilts returned to service \\
\hline Age at entry, days & $179.6 \pm 0.74$ & $180.0 \pm 1.35$ \\
Age at first mating, days & $257.2 \pm 1.08$ & $258.4 \pm 1.97$ \\
Age at first conception, days & $258.6 \pm 1.28^{\mathrm{a}}$ & $319.7 \pm 2.34^{\mathrm{b}}$ \\
Parity at removal & $6.18 \pm 0.10^{\mathrm{a}}$ & $5.57 \pm 0.18^{\mathrm{b}}$ \\
Lifetime pigs born alive & $69.7 \pm 1.2^{\mathrm{a}}$ & $61.9 \pm 2.2^{\mathrm{b}}$ \\
Female life day & $1,225 \pm 14$ & $1,198 \pm 25$ \\
Reproductive herd life day & $967 \pm 14$ & $940 \pm 25$ \\
Average pigs born alive/parity & $11.01 \pm 0.079$ & $85.0 \pm 1.08$ \\
Farrowing rate at parity $>1$ & $88.1 \pm 0.33$ & $4.77 \pm 0.107^{\mathrm{b}}$ \\
Lifetime productivity, & $5.33 \pm 0.06^{\mathrm{a}}$ & $6.24 \pm 0.108^{\mathrm{b}}$ \\
pigs/100 days & & \\
Reproductive herd life & $6.96 \pm 0.06^{\mathrm{a}}$ & \\
productivity, pigs/100 days & & \\
\hline
\end{tabular}

$\mathrm{a}, \mathrm{b})$ Means lacking a common superscript differ $(\mathrm{P}<0.01)$ in the same row.

or entry periods were not associated with age at first service or conception, longevity, lifetime pig production, or lifetime productivity $(\mathrm{P}>0.10)$.

\section{DISCUSSION}

Our analysis suggests that increasing age at first conception decreases longevity measured as parity at removal, lifetime pig production, and lifetime productivity in this group. For example, our findings suggest that 60 day delayed conception decreases female life day by 24 days, parity at removal by 0.024 , and lifetime pig production by 3.0 pigs. Furthermore, the lack of associations between age at conception and litter size (pigs born alive) in parities 1 and 2 indicates that there is no benefit in delaying matings beyond 230 days in this population. This observation is not consistent with reports showing positive effects in parity 1 and/or 2 sows [1,9]. However, the range of age at first conception in our study was older (10 and 90 percentiles: 227 to 322 days) than in previous studies that used relatively young age ranges between 180 and 245 days [1], 200 and 280 days [9], and 138 and 279 days [7]. It is possible that age at first conception within the relatively old ages (approximately 230 to 320 days) does not affect litter size at parity 1 because ovaries and uterus have been developed. In addition, increasing age at first mating decreases farrowing rate at parity 0 in our study. A biological mechanism behind the association between breeding at old age and low farrowing rate is not known.

We found a subpopulation in a REPEAT group of gilts which returned to service. These gilts had an older age at conception, were less fertile, less prolific, and removed earlier from a herd than those in the SUCC group. Based on these observations, REPEAT gilts present a problem when trying to optimize longevity, lifetime pig production, and lifetime productivity.

Our results reveal that sows in parities between 2 and 4 are the most fertile (i.e. farrowing rate) and those in parities 3 to 5 are the most prolific (i.e. pigs born alive). Our findings on lower farrowing rate at parity 0 than at parity 1 , and the highest litter size in parities between 3 and 5 are clearer than previous reports $[3,5,12]$, probably because of our unique data-set using females born during the same year. In our study, farrowing rate is the highest $(92 \%)$ at parity 2 and second highest $(91 \%)$ at parities 3 and 4, and declined to $80 \%$ at parities 9 and more. Furthermore, our study clearly indicates that litter size decreases from parities 5 to 10 .

This study is not a controlled experiment in the University, but an observational study using commercial farms. Animal environments such as housing, ventilation, or production management on all 33 farms cannot be identical or controlled. Therefore, the farm effect was included in statistical models to adjust for farm-to-farm variation. Even with such limitations, this study provides useful information on longevity for pig producers and practicing veterinarians.

ACKNOWLEDGMENT. The authors thank the Minnesota Agricultural Experiment Station for partly supporting this research.

\section{REFERENCES}

1. Clark, L. K., Leman, A. D. and Morris, R. 1988. Factors influencing litter size in swine: Parity one females. J. Am. Vet. Med. Assoc. 192: 187-189.

2. Dagorn, J. and Aumaitre, A. 1979. Sow culling: Reasons for and effect on productivity. Livest. Prod. Sci. 6: 167-177.

3. Hurtgen, G. P. and Leman, A. D. 1980. Seasonal influence on fertility of sows and gilts. J. Am. Vet. Med. Assoc. 177: 631635 .

4. Kroes, Y. and van Male, J. P. 1979. Reproductive lifetime of sows in relation to economy of production. Livest. Prod. Sci. 6: 179-183. 
5. Koketsu, Y. and Dial, G. D. 1997. Factors influencing the post weaning reproductive performance of sows on commercial farms. Theriogenology 47: 1445-1461.

6. Koketsu, Y., Dial, G. D. and King, V. L. 1997. Influence of various factors on farrowing rate on farms using early weaning. J. Anim. Sci. 75: 2580-2587.

7. Rozeboom, D. W., Pettigrew, J. E. Moser, R. L. Cornelius, S. G. and El Kandelgy, S. M. 1996. Influence of gilt age and body condition at first breeding on sow reproductive performance and longevity. J. Anim. Sci. 74: 138-150.

8. SAS. 1988. SAS/Stat User's Guide. Statistical Analysis System Institute, Cary, North Carolina.

9. Schukken, Y. H., Buurman, J., Huirne, R.B.M., Willemse, A.
H., Vernooy, J.C.M., van den Broek, J. and Verheijden, J.H.M 1994. Evaluation of optimal age at first conception in gilts from data collected in commercial swine herds. J. Anim. Sci. 72: $1387-1392$.

10. Smith, R. D. 1991. Veterinary Clinical Epidemiology: a Problem-oriented Approach. Butterworth-Heinemann, Stoneham, Massachusetts.

11. Steel, R.G.D., Torrie, J. H. and Dickey, D. A. 1997. Principles and Procedures of Statistics: A Biometrical Approach 3rd., McGraw-Hill Publishing Co., New York.

12. Yen, H. F., Isler, G. A., Harvey, W. R. and Irvin, K. M. 1987. Factors affecting reproductive performance in swine. J. Anim. Sci. 64: 1340-1348. 